\title{
Policy Implementation on the Rice of in Order to Increase Food Stock in Rembang District
}

\author{
Suparno ${ }^{1}$ \\ ${ }^{1} 17$ Agustus 1945 University, Semarang, Central Java, Indonesia \\ Correspondence: Suparno, 17 Agustus 1945 University, Semarang, Central Java, Indonesia. E-mail: \\ jenewa.alexandra@gmail.com
}

Received: January 26, 2018

Accepted: February 8, $2018 \quad$ Online Published: February 27, 2018

doi:10.5539/mas.v12n3p84

URL: https://doi.org/10.5539/mas.v12n3p84

\begin{abstract}
Food stock has become a concern of the Government since before the independence days. The Government always seeks to maintain food security so that the community would be sure needs their meal.The development of food security policy since the days of old order up to this time show the concentration of policies that are more or less the same, namely the availability of rice as a staple food. The purpose of this study is to: (1) decsribe and analyze the policy implementation on the rice availability in order to increase food security in Rembang District. (2) Describe and analyze what factors that support and hinder the policy implementation on the rice availability in order to increase food security in Rembang District. (3) Formulate a policy implementation model of rice availability in order to increase food security in Rembang for five years into the future. This research used a qualitative approach and including phenomenological research, with the research instrument of the researchers themselves. Data sources informants specified in purposive sampling, observation and documentation as well as supported by technical discussion. The results of this research indicate in general implementation of the food security policy in particular the rice availability in Rembang has not been implemented to its full potential, as well as the achievement of results. Rice availability policy implementation model proposed, namely: (1) increasing coordination with Regional food security Board optimization of Rembang, (2) Formulating policy areas which are more tangible, a clear change of degree movies, and the support of stakeholders be optimized especially from the head Area, (3) communication is increasingly clear through the medium of a simple but striking. (4) The structure of the organization or the bureaucracy that comes with it's SOP.
\end{abstract}

Keywords: policy implementation, rice availability, food security, management policy, security and rembang

\section{Pendahuluan}

Globally, rice is a very important food crop. It is an ancient crop consumed as healthy and staple food by more than half of the world population. Rice is consumed by over 4.8 billion people in 176 countries and is the most important food crop for over 2.89 billion people in Asia, over 40 million people in Africa and over 150.3 million people in America with estimates based on FAO report of 1996. More than $90 \%$ of global production occurs in tropical and semi-tropical Asia (Daramola, 2005).

Rice is a staple food for over half of the world's population especially in Asian region. Rice accounts for over 20 percent of global calorie intake (Wailes, 2003). Over 90 percent of the world's rice is produced and consumed in the Asian Region with 6 countries (China, India, Indonesia, Bangladesh, Vietnam and Japan) accounted for 80\% in the world's production and consumption. Recently, Asian trend shows the production and export has been increasing but the consumption is decreasing. With growing economic prosperity and urbanization, per capita rice consumption has started to decline in the middle and high-income Asian countries like Japan, Taiwan and the Republic of Korea. But, nearly one-fourth of the Asian population is still poor and has considerable unmet demand for rice such as Afghanistan, North Korea, Nepal and Vietnam. It is in these countries that rice consumption will grow faster. The decreases of rice consumption in Asian region are because of the increases in per capita income that leads income elasticity's of demand for rice as a normal good decreasing as well as westernize in diet.

In ligih of this food security according to Government Regulation no 68 in 2002 about food security are: "The conditions of food to satisfy of the household that is reflected from the availability of foods sufficient, both of 
number nor its quality, safe, equitable and affordable". Thus food security is the condition of the food for the correct fulfillment of households and individuals in sufficient amount and quality of a good, safe, affordable, equitable and guaranteed availability. In developing countries such as Pakistan, India and Bangladesh food security policy is focused on the safety and availability of food. In Bangladesh, as stated by the National Strategy for Accelerated Poverty Reduction food policy nationwide.

In Bangladesh, (Mirsha 2010), food security is placed on top priority, alongside the food production in the country. Greater importance that is given to ensure access to sufficient and safe foods is along with everyone all the time to keep active and healthy life. So too in Pakistan food availability policy directed at food availability: i.e. when sufficient amount of food to meet the needs of its inhabitants. The Constitution of Pakistan mentioned in article 38 that the State provides basic necessities including food of its inhabitants.

The two countries is nearly no difference with Indonesia in order to maintain availability and food safety. The problem of food security in both those countries is more or less the same, namely the increase in food production. While in India which has the world's third largest population, food security is quite a concern. National Development Agency of India taking the Mission of food security includes rice, wheat and beans. The Government is trying to increase production of these foodstuffs to third on condition that enough. Conditions in India always pay attention to the availability of the three foodstuffs, namely rice, wheat and beans which became the staple food of the people of India. The Government of India took a policy related to the increased production of rice, wheat and beans are tiered with the primary focus on increasing the production of rice. Thus the Mission of the food security policy has three components.

In Vietnam, Chantal Pohl (2001): "Vietnam's Rice Policy: Recent Reforms and Future Opportunities". In the reform of agricultural policy, to increase productivity, farmers were given various incentives to encourage its productivity, liberated the various types of taxes. For example: taxes land use, irrigation, agricultural machinery import tax. This aims to encourage agricultural productivity.

Similarly, in Thailand, Vikram Nehru (2011): "Thailand's Rice Policy Gets Sticky Thailand's Rice Policy Gets Sticky, "where the Government gives strong support in issuing a policy strategy that will prospect on the farm. One of them through the target expansion of agricultural lands (rice fields) reached 9.2 million hectares.

While in Indonesia the food security has become a concern of the Government since before the independence days. The Government of Indonesia has always strived to maintain food security so that the community would be sure Indonesia needs their necessity. Food security policy developments since the time of old order up to this time show the concentration of policies that are more or less the same, namely the availability of rice as a staple food.

The policy of food security in Indonesia during the old period, Mr. President in that time namely Soekarno take the policy of food security by focusing on the availability and security of the food for the community and especially the civil servants and the military. The policy was taken at that time was the rice self-sufficiency of rice policy program through Kasimo Plan (Plan of Kasimo) in 1952 - 1956 rice self-sufficiency program also via sentry of rice program during 1956-1964. (Jonatan Lasa, 2007). The Government of President Sukarno attempted to meet the food needs of Civil Servants and the military as political support, but not so the attention on the community. The price of rice and other foodstuffs could not affordable by the community. Rice in particular is very expensive food for the people (Mears and Moejono, 1981).

Since the beginning of the New Order Regime known as (Orba), food security policy based on the Orthodox paradigm, namely the provision of foodstuff (Food Availability Approach = FAA). The paradigm of the FAA holds that a country's food security is defined by its ability to provide basic food in quantities sufficient for the whole population. The FAA did not pay attention to the aspect of distribution and access to food because this approach assumes that if the food supply is available then the traders will transmit to all areas of the food efficiently and food prices will remain stable in the level can be reached by the whole family (Panjar Simatupang, 2007). National food conditions at the beginning of the new order Government's great concern. The Government at the time it was confirmed that the progress of the country seen from industrial development towards a sophisticated industry will be very dangerous if left agriculture.

The Government of Indonesia in 1996 passed a law on foodstuff, namely Costitutional Laws No. 7 in 1996 about Food. According to the law is defined as a condition where the occurrence of adequacy of food for households that measured from the food necessity in terms of number and quality and also there is a guarantee of top security, equitable and distribution in the ability to buy. The law on the food followed up with government regulations, namely the promulgation of Government Regulation Number 68 year 2002 about food security. The Governmental regulations defining food security is a condition of food to satisfy household food availability are 
reflected from hygines, good number of nor quality, secure equitable and affordable. Thus food security is a condition to satisfy with a sufficient amount of food, available at any time in all regions, easily obtained household, safely consumed, and at level an affordable price.

National policy relating to food security includes three aspects: availability, distribution, food diversification and food security. Food security policy is stated in Constitutional Laws No. 12 in 2007 about the National Long-Term Development Plan known as (RPJP N) and Presidential Regulation No.5 in 2010 about National Medium Term Development Plan during 2010 - 2014. This aim for economic development and prosperity, especially in the fields of food, is the creation of self-reliance in the field of food by the end of 2014.It is characterized by increasing people's food security, the improvement of nutritional status of mothers and children in the community that food insecurity, improving access of the poor households to food, preserved and ever-increasing ability self-sufficient in rice and other major food commodities, keep food prices affordable to the lower middle income group society, keeping the exchange rate so that farmers can enjoy prosperity, and increase bargaining power in Indonesia commodities and comparative advantage (comparative advantage) of the Indonesia's agricultural sector in Asia Region and globally. In addition the Affairs of food security also became one of the eleven national priorities within the framework of national development (The National Medium Term Development Plan 2010 - 2014).

One of the results of the Presidential Instruction in Central Java province up to this time (in 2012) is a program of community-based poverty reduction empowerment is one of which is the implementation of a National Community Empowerment Program known as (PNPM) Independent Countryside. This program is one of which the provision of infrastructure in the Village to increase agricultural production, one of which was rice. This activity has been running long enough, and the result is felt has not been optimally felt by the community especially in terms of increased agricultural production, especially rice (Report Description Of Liability abbreviated as LKPJ) the Governor in 2011).

The food security policy of Central Java Province is contained in Long Term Regional Development Plan abbreviated as (RPJPD) document of Central Java province during 2005 - 2025 and Medium-Term Regional Development Plan during 2008 - 2013. In Central Java Province RPJPD 2005 - 2025 about food security policy is directed to: "development of agricultural products, fisheries, marine, forestry and agribusiness system resting on the supported facilities and infrastructure are adequate to ensure the food self-sufficiency and food security".

\section{Previous Research}

\section{a. Trade Policy and Nigeria Rice Economy}

By: Busari Ahmed. O and Idris-Adeniyi K.M, Department of Agricultural Economics and Extension, Osun State University, Osogbo College of Agriculture, Ejigbo Campus, Osun State, Nigeria

Rice is an important crop in the economy of a developing nation like Nigeria. Available statistics have shown that the country is yet to attain self-sufficiency in rice production. Hence, government had to retort to massive importation in order to bridge the supply-demand gap. Rising bills of rice importation over the years have been depleting the country's foreign reserves. This had led to the evolution of three (3) trade policies regime (the pre ban period (1970-1985), the ban period (1986-1995) and post ban period (1997-2010)) by successive government to arrest this trend. This study analyzed the response of domestic production and demand of rice to importation under these policies regime. Secondary data on domestic production, demand and importation of rice from 1970 to 2010 were analyzed with both descriptive and inferential statistical tools. Descriptive analysis results showed that the mean domestic production of rice for pre ban, ban and post ban period were 728.87, 2165.82 and 6293.33 metric tons respectively. While the mean domestic demand of rice was $1214.19,3525.00$ and 3931.17 metric tons during the pre-ban, ban period and the post ban period. Analysis of variance (ANOVA) results indicated that there is significant difference in the means of domestic production and demand of rice during these periods. The elasticity coefficients for domestic production and demand for pre and post ban are $0.98,1.60,-0.15$ and 0.14 respectively. The study concluded that government should stimulate expansion of domestic production of rice while phasing out rice importation gradually.

\section{b. The Impact of Rice Production, Consumption and Importation in Nigeria: The Political Economy Perspectives}

By: Terwase, Isaac Terungwa; Madu, Abdulrazak Yuguda, Ghazali Shafie Graduate School of Government, College of Law, Government and International Studies, Universiti Utara Malaysia, Sintok, Kedah, Malaysia

Nigeria's population is estimated at $174,507,539$ with the annual growth rate of $2.54 \%$. The country is endowed with enormous mineral and natural resources with vast land adjudged to be the most fertile and suitable for 
agriculture. Rice demand and consumption is high among its people irrespective of their region or culture. This paper attempts to investigate the level of the country's production, consumption and importation of rice, with a view to establishing its impact on its economy and development. The methods adopted for obtaining data for the study were purely empirical and secondary. It was found amongst others that; while the level of production of rice is low, the consumption is high and its importation is highly inelastic. It was recommended that, deliberate attempts must be made by government in terms of policy to improve its agricultural base particularly in rice production not only as a substitute for its importation and domestic use, but export as well. This will go a long way in increasing foreign earnings, which can be replicated, and serve to complement the country's economic growth and development.

\section{c. World Rice Demand Towards 2050: Impact of Decreasing Demand of Per Capita Rice Consumption for} China and India

\section{By: ALIAS Abdullah, Hajime KOBAYASHI, Ichizen MATSUMURA, Shoichi ITO}

Rice is a staple food for over half of the world's population especially in Asian region. Rice accounts for over 20 percent of global calorie intake (Wailes, 2003). Over 90 percent of the world's rice is produced and consumed in the Asian Region with 6 countries (China, India, Indonesia, Bangladesh, Vietnam and Japan) accounted for $80 \%$ in the world's production and consumption. Recently, Asian trend shows the production and export has been increasing but the consumption is decreasing. With growing economic prosperity and urbanization, per capita rice consumption has started to decline in the middle and high-income Asian countries like Japan, Taiwan and the Republic of Korea. But, nearly one-fourth of the Asian population is still poor and has considerable unmet demand for rice such as Afghanistan, North Korea, Nepal and Vietnam. It is in these countries that rice consumption will grow faster. The decreases of rice consumption in Asian region are because of the increases in per capita income that leads income elasticity's of demand for rice as a normal good decreasing as well as westernize in diet. The Asian population is growing at 1.8 percent per year at present. Growth in population in this region means the increases on demand for rice (for total consumption but not per capita consumption). So far the annual growth rate for rice consumption in the Asian Region over a period of 48 years (1960 to 2006) has kept pace with the demand, more through yield increase rather than area expansion. Improved varieties have made a significant impact on the demand side in an ever increasing order during this period. The world rice production has more than doubled from 150.8 million tones in 1960 (with Asian production of 134.4 million tones) to 414.7 million tones in 2006 (including the region's production of 364.0 million tones). For almost two decades, from the mid-1960s to the mid-1980s, rice production grew at close to $3 \%$ per annum. Slower growth since the mid-1980s has been influenced by both supply and demand factors: sharply lower prices for rice, environmental degradation and over-exploitation of soil and water resources, and a decline in per capita consumption with the rising of household incomes in Asian regions.

\section{d. Efficiency of the Dojima rice futures market in Tokugawa-period Japan}

By: Shigeru Wakita; Faculty of Economics, Tokyo Metropolitan University, 1-1 Minami-Osawa, Hachioji-shi, Tokyo, 192-0397 Japan

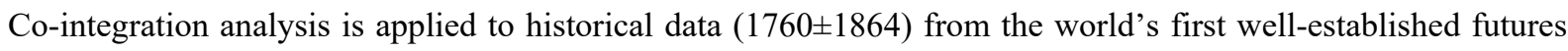
market, in rice at Dojima (in Osaka, Japan). The market shows a strong seasonal character. The summer market was strongly characterized by producers hedging behavior, and may be called a "commodity-oriented futures market". On the other hand, the spring and autumn markets in the middle of Tokugawa era were "financial" markets, characterized by the unbiasedness hypothesis from the theory of rational expectations.

\section{e. The Dojima Rice Market and the Origins of Futures Trading}

When Tokugawa Yoshimune became Japan's shogun in 1716, he sought to reform the state's finances. Rice played an important role in his reforms, since it accounted for 90 percent of the government's revenues. The shogun ate also paid the banner men (an important group of samurai who formed the civil and military administrations) fixed amounts of rice each year to secure their support. a Low rice prices in the late 1720s strained the samurai's finances, which had already deteriorated significantly over the previous century. Potentially as a result of several good harvests, the price of rice in 1729 was only 40 percent of what it had been in 1721, and samurai incomes had thus dropped sharply.2 In fact, since 1710 the nominal income of the banner men had fallen by nearly 50 percent, and their real income had also decreased significantly, though less so since other prices had dropped as well. With the development of urban districts, the chonin [merchant/artisan] class gained increasing influence, and the currency economy made so much development as to challenge the supremacy of the land economy. That is to say, a new economic power, viz., the money power of the chonin class, sprang up, besides [sic] the agricultural economic power. Due to this remarkable economic change, it became 
impossible for the samurai class to maintain its livelihood under the old economic organization. Nor was it any longer possible for the farmers to support the samurai class. In such circumstances, samurai finally bowed to the new economic power. They either be sought the financial help of chon in or turned chon in themselves. On the other hand, the chon in class gained considerable influence in society by means of its money power.

\section{Research Method}

The study, "policy implementation on the rice of in order to increase food stock in Rembang District", is a study that is both specific and holistic. Specifically referred to the subject of research is the bureaucrats (the perpetrators) and the availability of rice fields on the implementer in order to increase food security. Holistic referred to that study in this research not only concerns the socio-economic aspects, but also the public administration. Considering the peculiarities and the subject, the object of the research as well as the nature of the research, then this study using a research approach to qualitative and include the type of phenomenological research. According to Strauss and Corbin (1980), qualitative research is the kind of research that produces inventions that cannot be reached (obtained) by using statistical procedures or by other means and quantification (the measurement).

Strategy approaches or other types of qualitative research used in this study is a naturalistic approach (Lincoin and Guba, 1985; Lee, 1999). Qualitative research according to Strauss and Corbin (2003), is a type of research that produces inventions that cannot be achieved using statistical procedures or with other ways of quantifying (the measurement). Naturalistic research is research that the source of the data retrieved from the situation it is natural (natural setting) or without any manipulation. More researchers are using a method definition (verstehen), as the subject's sense of capture ability/empathetic of informant (emic) which is then ejected back in those thoughts researcher (ethic) about the feelings, motives and thoughts that there is behind the actions of informants.

Through naturalistic approach, researchers can figure out a response and the perception of various backgrounds, such as against the policy actors on the relevant agencies and bodies, the apparatus is on the front-lines bureaucrats involved in the implementation of the policy on the availability of rice in order to increase food security in Rembang District.

To further sharpen the research, then the researcher sets the focus of the research. Focus of the research assignment according to Strauss and Corbin (2007:10) aims to: first, set the focus limits the study of meaning with the focus, determination of research sites that are more feasible. Second, the determination of focus effectively set criteria of inclusions to trawl the information flows in. So necessary because, sometimes, while in the field, Researchers obtained data is pretty good, but if the data retrieved is not relevant to the focus of the research, of course does not mean that data and not noteworthy. How means a focus on research, Moleong (2000) suggested that the focus of the research is very important role in the research that can be used as a means to guide and direct the research. With the direction of the focus of the study, Researchers will be able to know exactly where the data is needed and needs to have the collection.

The research is the qualitative research "it is the determination of the purposive sampling conducted in the informant. Informants were selected to be interviewed are those which, according to the researcher has sufficient information relating to the rice availability in Rembang District. The technique of taking informants was chosen because the information about food security particularly regarding the availability of rice not everyone understands. The source of the data in this study is, the informant; to determine informants in this study considered the background actors, events and processes in accordance with the framework and the formulation of the problem (Miles and Hubermen, 1984; Sugiono, 1993; Moleong, 2000). Since the information from the beginning has been determined (purposive sampling), assuming it has the needed information.

Based on this, then informants in this study was the Informant who are directly involved in the implementation of Government policy in the area of implementation of handling food security particularly regarding the rice availability in Rembang District. Informants were selected in this study was the apparatus or officials have the authority and competence of local government policy in handling the implementation of food security especially concerning the rice availability in Rembang in the field of the rice businessmen, farmers, farmer groups, and provider of pest sprays.

\section{Result and Discussion}

\section{a. The Process of Rice Availability Policy Assignment}

The food security policy stated in government regulation Number 68 in 2002 concerning food security is encapsulated in the situation of reform and the enactment of the new autonomous region runs a little over two 
years. Thus the Affairs of food security are a relatively new about 10 years left to the Governments District/City. The process of the determination of the policy at the time wasn't yet fully pay attention to the readiness of the District/City to receive such Affairs. As conditions in the Government Regulation district/city and province has a task as enshrined in articles 13 and 14 this Regulation.

Based on the provisions of article 13 and 14 Government Regulation that the task looks Rembang is not light. The main task in the field of food security was responsible for organizing the food security in this region. Thus Rembang District is responsible regarding food security in its territory, namely by observing some aspect i.e. the availability, distribution, rice affordability, equitable distribution of food, food safety and food diversification. Rembang District Government should be able to afford food availability in particular rice for its inhabitants. Not only provide but rather distribute it throughout all corners of Rembang District at affordable prices by the inhabitants of the poorest. Rembang District Government must also be able to ensure that the food that is consumed the community is safe.

Increased availability of rice policy formulation as defined in Government Regulation No.68 in 2002 in Rembang District is done through the process of planning the construction of a five-yearly and annual development planning. Food security of policy formulation process is done through the process of the preparation of Medium-Term Regional Development Plan known as RPJMD and Regional Development Work Plan known as RKPD. In the process of preparing RJMD of Rembang during $2010-2015$ outlined the problems and issues of their respective strategic Affairs, subsequently formulated objectives, strategy, direction and activities policies and programs each affair. Materials used for preparation of RPJMD input comes from Strategic Plan (Renstra) Work Unit (SKPD) Area of the device, which is planning the construction of a five-yearly at the level of the SEGWAY.

In the Medium-Term Regional Development Plan RPJMD of Rembang District load direction development policy as much as 34 Affairs i.e. 26 mandatory Affairs and 8 option Affairs. Food Security Affairs is one of the 26 mandatory affairs. As the stages of preparation of RPJMD, the formulation of policy directions food security begins with the depiction of past performance indicators are close to food security. In accordance with the provisions of Regulation of the Minister of Agriculture abbreviated as Permentan 65/Permentan/140/12/2010 Minimum Standards of food security areas of the province and district/city, availability of food reserves in 2015 should be of $60 \%$ and availability of energy and protein of $90 \%$ in 2015 . The condition of availability of food is especially food reserves in preparation of RPJMD depicted in series a few years ago. Based on past performance data related to the availability of food or rice then formulated the strategic issues. Based on the strategic issues formulated goals and objectives and policy directions and programs and activities.

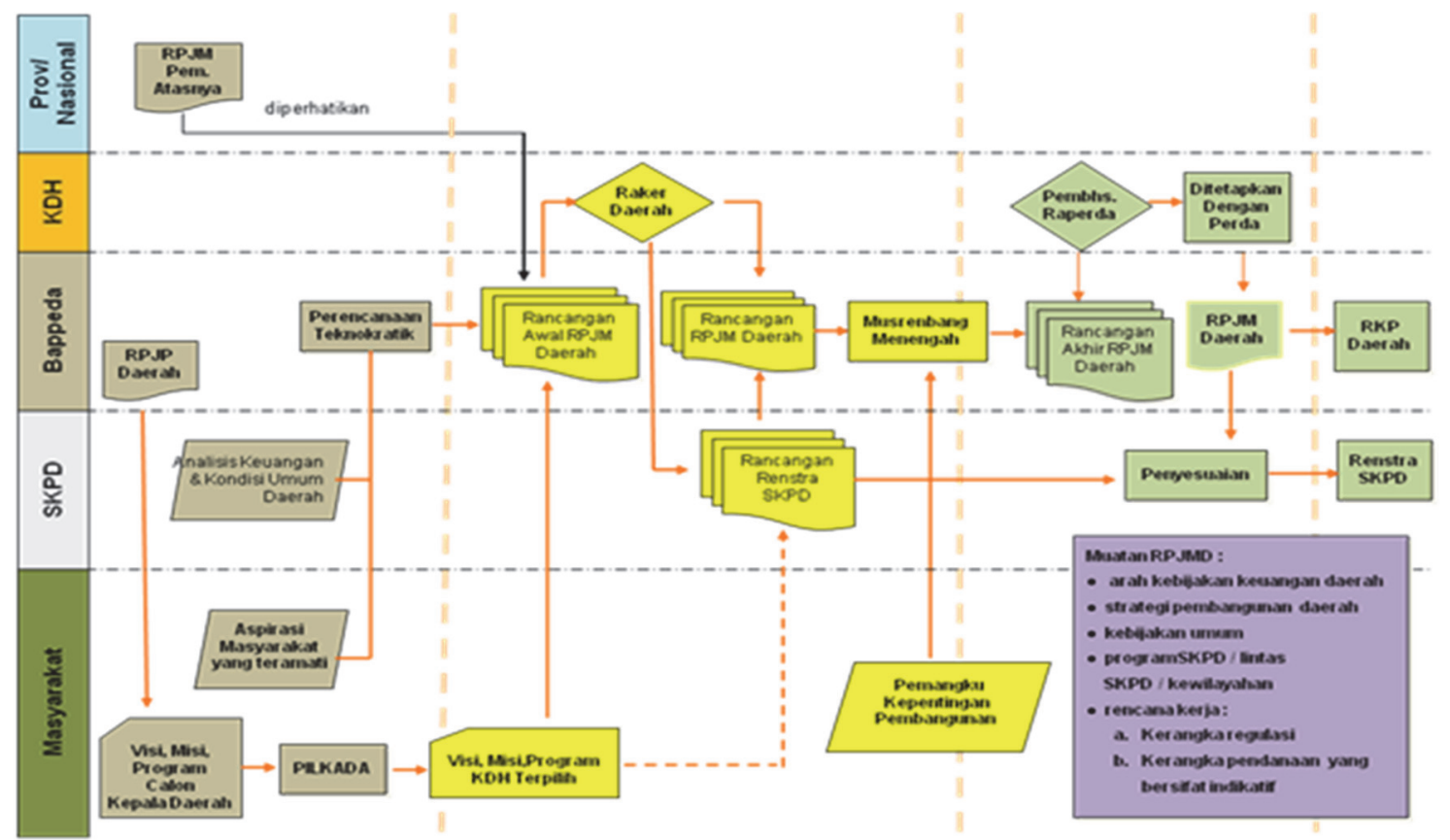

Figure 1. The Arrangement Process of RPJMD

Source: Regulation of the Minister of the Interior 54 in 2010 
The diagram above illustrates the preparation process of RPJMD that contain of policy on food security. Thus analogous to the preparation of RPJMD, the food security policy formulation is through participatory processes, technocratic and political. Food security policy formulation in Rembang District is gone through long stages of discussion many times.

Increased availability of rice policy formulation as defined in Government Regulation No.68 in 2002 in Rembang District is done through the process of planning the construction for five-yearly and annual development planning. Food security policy formulation process is done through the process of the preparation of RPJMD and RKPD. In the preparing process of RJMD Rembang during 2010 - 2015 outlined the problems and issues of their respective strategic Affairs, subsequently formulated objectives, strategy, direction and activities policies and programs each affair. Materials used for preparation of RPJMD input comes from Strategic Plan (Renstra) Work Unit (SKPD) Area of the device, which is planning the construction of a five-yearly at the level of the SEGWAY.

Based on the description it can be concluded that the County Government has the perfect follow through Government Regulation No.68 in 2002 about food security. It looks in the preparation of RPJMD containing the Affairs of food security as one of 26 mandatory affairs. Food security policy formulation is loaded together with other affairs policy in document RPJMD strategic issues formulated in the next. Based on the strategic issues formulated goals and objectives and policy directions and programs and activities.

\section{b. Policy Formulation, Program and Activity of Rice Availability}

In a development planning process of the formulation of policies, programs and activities are always based on strategic issues or problems. Policies, programs and activities should ideally be used to solve the problems or issues that arise. Likewise than contain in the setting of the program and food security activities in Rembang District.

Formulation of policy directions, programs and activities in the framework of food security especially the rice availability is done together in a coordination meeting called Forum with SEGWAY in order the preparation of RPJMD Rembang District during 2010 - 2015. In the forum formulated the direction of policies, programs and activities to especially food security the availability of rice poured in document RPJMD Rembang. The formulation of policies, programs and activities is the implementation of Government Regulation 68 in 2002 about food security. The direction of policies, programs and activities is a description of what will be achieved and done by Rembang for five years into the future in order to carry out the Affairs of food security especially in maintaining the food availability especially for rice.

This policy direction is in fact the implementation efforts of the Organization of the food security as mandated in Government Regulation No 68 in 2002. Policy implementation of the food security as stated in Government Regulation No 68 in 2002 is implemented in the direction of policies, programs and activities at the local level are listed in the RPJMD and Renstra P4K and Food Security Agency. The area is responsible for the implementation of the food security so that the region must create local policies to implement food security.

Based on the description can be concluded that between a policy that is stated on the RPJMD of Renstra Agency and on food security and food availability policy P4K particularly availability of rice already in line, as a form of implementation of Government Regulation No 68 in 2002, with the aim of seeking the availability of rice through the establishment of policy on food availability and food reserves that meet the quality, quantity for the community as well as the diversification of food products, up to the 2015 .

\section{c. The Condition of Rica Availability This Time}

The condition of the rice availability reflects the readiness of the region to serve the community in meeting the rice necessity. The condition of availability is the comparison between the production and consumption of rice or the form of the difference between production and consumption in the span of one harvest season or a year. The difference between consumption and production of rice this is the rice availability accounted for the ability of the region to meet the rice necessity for community. The rice availability there is two possibilities that surplus and deficit while conditions of production equals consumption included in the deficit. Conditions of production is equal to deficit areas zoned consumption do not have enough food reserves to meet the needs of its residents or citizens of the society.

Food reserves is very important for a country's food security, including the State of Indonesia is an agrarian. Since 2005, the Government has had the Government's Rice Reserve (CBP) managed by BULOG, blends with the stock of BULOG and accessible in each warehouse BULOG across Indonesia by the Government.

$\mathrm{CBP}$ is a number of specific government-owned rice which is the source of the funding comes from the State 
Budget and managed by the BULOG which used to cater to the needs of society and rice in order to anticipate the problem of food shortages, pricing turmoil, State of emergency resulting from disasters and food insecurity. The benefits of the existence of the CBP have been tested in the handling of a variety of natural disasters in the country. Rice that has been available in the warehouses BULOG which is fairly spread throughout the homeland can be immediately utilized by provincial governments and district/city Governments for use in meeting food needs for displaced disaster victims.

According to Constitutional Laws No. 7/1996 of the food mentioned that food is a basic human needs be any rights the people of Indonesia. Food is determining the level of the community welfare sector in rural and poor communities/consumers in urban areas. According to Government Regulation No. 68 in 2002, about food security, explained that food security is a condition to satisfy food for households that are reflected from the availability of foods sufficient, good number of nor quality, secure, equitable, and affordable. There are three pillars of food security that must be realized at any time and in any place namely the availability (availability), affordability physically (accessibility), and economic stability \& (stability).

Rice is a staple food that is produced by many farmers and consumed by the majority of society Indonesia. Rice is the policy efforts of increasing food security. In the history of rice in Indonesia had never been separated from the role of Government to participate in organizing the national rice economy. This is because the release at all government intervention in national the risks are enormous. The Government has never changed fundamentally national of rice policy objectives being done during these still revolve around maintaining the viability of domestic rice production, protect the rice farmers as well as ensure the sufficiency of rice for the community so they get easy access to physical as well as economically sustainable.

Government intervention in the economy, among other rice done through food served in Governments implement policies that concern both the rice aspects of pre production, production process, as well as post production. The organization food that is given the task of the Government to address the issue of post production, particularly in the areas of pricing, marketing and distribution is the State Logistics Agency (BULOG). Institutions such as BULOG has been around since the days of colonialism, when the Netherlands prior to the occupation of the Netherlands known as VMF, colonial rule Japan known as Sangyobu Nanyo Kohatsu Kaisha, or also at the time of independence that many experience changes since from PMR, BAMA, YUBM, BPUP, Kolognas and BULOG. The duties and functions of the food agencies are generally revolves around the issue of control pricing, distribution and marketing. Only the main focus can differ between time and between these institutions.

BULOG is a government agency established in 1967 which was commissioned by the Government to control price stability and the provision of staple, especially at the level of the consumer. BULOG's role was developed again with producer price plus control through the instrument base price to protect farmers ' rice. In a further development, the role of BULOG is not only limited to rice alone but also on controlling prices and the provision of other commodities such as sugar, wheat flour, soybean and livestock feed, cooking oil, eggs and meats as well as herbs- flavor, which carried out incidental situations especially when the price increases.

Before in 1998, the task given to the BULOG intended to control prices and maintain the stability of the producer price of rice consumers, as well as providing rice stocks between time and an area for the purpose of connecting Government and backup routine for the purposes of emergency or other purposes. Weight control the producer price and consumer price balanced. Starting in 1998, BULOG back only handle rice. The task given to the BULOG also experienced changes due to changing rice policy of the Government does. Protection to farmers through a price floor remains a top priority. As for the stabilization of consumer prices diminished in line with the continued controlling of the domestic rice price. Instead the role of BULOG to help the poor that food insecurity is increasingly prominent.

\section{d. The Policy Analysis Of Rice Availability}

The implementation process of existing rice availability policy based on the survey results is beginning from the determination of the rice availability policy. The process of drafting is illustrated the policy assignment issue or agenda setting. The problems that arise with regard to the availability of rice is increasing the rice availability in Rembang until 2015. Surplus rice in Rembang until 2012 is about 57,541 tons. The policy is taken to solve these problems is "provided the food availability and access of society to food quality, nutritious, safe and affordable".

Should the formulation of policy at district level Rembang also must wait for the Council's role as a Regional food security forum of policy makers about food security. In normative Council of greater food security are already formed is supposed to formulate a regional food security policy however until the end of the year 2012 has since formed the Council of food security chaired by Rembang District (former official) yet undertake 
activities of any kind. Regent less focus towards greater food security, according to this result is not visible as a monument for governmental, so do not prioritize the Regent food security as one of the program's successful.

The food security policy of Rembang District decided not through the Council for food security, but through the mechanism of the preparation of RPJMD and Renstra SEGWAY leverages the momentum of preparation of RPJMD in early Government Regent. From the analysis above, the proposed process of policy formulation should be. Food security policy formulation included the availability of rice should be based on the results of the Coordination Meeting with the agreement of the Council of food security in the year in question. Furthermore, in the formulation of policies should also be based on the needs of the community are chosen through the Regional Development Planning discussion forum annually.

\section{Conclusion and Suggestion}

\section{A. Conclusion}

Based on the research results obtained findings many obstacles faced in the policy implementation of the food security in particular the of rice availability in Rembang. The process of drafting the policy assignment contain on issue or agenda setting. The problems that arise with regard to the rice availability are increasing the rice availability in Rembang until 2015. Surplus rice in Rembang until 2012 is about 57,541 tons. The policy is taken to solve these problems is "provided the food availability and access of society to food quality, nutritious, safe and affordable". Rice availability policy assignment is done via the process of formulation of RPJMD as contained in Government Regulation 8 in 2008 about guidelines, treatment and evaluation of local development Plans. Determination in PARLIAMENT did not explicitly put forward the Agenda Setting, about food security to resolve problems related to food security but rather caused by the demands of regulations (normative). Rice Availability policy formulated Government Rembang was the implementation of Government Regulation No 68 in 2002 and Government Regulation 83 in 2006. Policy formulation in Rembang District level also must wait for the Council's role as a Regional food security forum of policy makers about food security. In normative Council of greater food security are already formed is supposed to formulate a regional food security policy however until the end of the year 2012 has since formed the Council of food security chaired by Regent Rembang (ex-official) yet undertake activities of any kind. The food security policy of Rembang decided not through the Council for food security, but through the mechanism of the preparation of RPJMD and Renstra SEGWAY leverages the momentum of preparation of RPJMD in early Government Regent.

Based on the results of the research with the informant can be concluded that the rice availability in Rembang in 2012 is relatively sufficient to meet the needs of Community rice in the upcoming 2013 until the next harvest season. Some areas of paddy rice production drape rainwater need to gain attention because during the dry season they threatened shortages of rice. At the time the research was conducted in rice availability conditions experienced surplus 57,541 tons. Analysis of the management to keep the availability of rice in Rembang includes an overview and study how the Government plan, implement and evaluate policies toward maintaining and improving the availability of rice on the Regency Rembang. Description and study of management of rice availability is beginning with planning, organizing, implementing and monitoring and evaluation.

Policy implementation on the availability of rice also performed with collaborating with a group of farmers. The role of the Group of farmers or farmers themselves more on efforts to increase the production of rice.BKP and $\mathrm{P} 4 \mathrm{~K}$ as the institutions also have a duty to perform agricultural extension to farmers play a role by giving farmers cultivate guidance to farmers on a regular basis and are routine. The role of farmers and farmer groups in maintaining food security especially the availability of rice is seeking so that farmers have food reserves sufficient to meet family needs. Item trader has an important role in maintaining the availability of rice in one region. This is what traders do rice distribution to the community. Traders with his trademark instincts do the selling and distributing rice to the community. Traders also set the selling price of rice in accordance with economic principles by taking a certain profit margin for them. Determination of rice prices is very depending on the market mechanism. This means that the selling price of rice is very depending on the supply and demand of rice in the community. In addition, according to traders in rice prices largely determined by the price at the level of trader which usually have business rice mill. When rice was scarce at the time or not yet harvest season is usually the price at the rate of trader is already high.

Mechanisms of monitoring and evaluation of the rice availability is done periodically or as needed. The period of monitoring and evaluation of the availability of rice on a regular basis is conducted each month by the clerk BKP. Monitoring also performed at a time when the price of rice rose by drastic. Mechanisms of monitoring and evaluation of the availability of rice on the diagram above is too simple regardless of the various perpetrators of other businesses or other stakeholders as well as less Standard Operating Procedures (SOPs). 
Policy on the availability of enough rice, secure, good quality and affordable by the community, the benefits of this policy for the community not directly can be enjoyed by the target group. The public is less likely to understand the policy of the availability of the rice, but for farmers benefit directly from this policy had already been felt. Through the policy of increasing the availability of rice of course followed by the increase in rice production, and the Government is facilitating increased production with a variety of programs that touch directly PUAP, among others, farmers SLPTT, Sapta Effort Farmers, planting rows of patterns and so on. The program is directly beneficial to farmers to boost rice production which in turn will increase the income of farmers.

The degree of change expected from policies the availability of enough rice, secure, good quality and affordable by the community is a change in the way the rice farming of the conventional into the pattern Rows; changes to food diversification by not eating rice a day within a year. Changes for society to reduce the consumption of rice society still do not correspond to the expectations because the community particularly farmers don't want to not eat the rice in one day. They provide a reason that these changes be felt heavily. Farmers are not strong in a day do not eat rice.

In the implementation of the policy program improves the availability of enough rice, safe and affordable, one of the implementation done is Increased the food security Office in Rembang became the Agency's food security and Implementing Extension agriculture, plantations and forestry (BKP and P4K); Community involvement is quite good, particularly the Group of farmers as well as ctively involved in food security program; Yet the realization of integration and synergize between stakeholder related, still appeared ego sector and overlap in implementing their task; Yet the realization of integration program between stakeholders with one another; Regulatory support and advice infrastructure are still limited. The resources involved in the implementation of this policy are a resource in its own level of bureaucratic problems in the implementation of the policy of food security. Bureaucracy is the main implementers must be able to move communities to carry out what is expected of the Government through policies that are drafted.

\section{B. Suggestion}

Based on the presence of some of the obstacles in the policy implementation of the food security in particular the availability of rice, then researchers recommend a few things as follows:

1. In order for the policy "of non government organizations of sugar" from Central Java Province Government does not conflict with the policy of the availability of the rice, it needs to be disseminated to the Community/farmers so that the farmers in productive paddy fields is not switched on the plant cane.

2. The Council's coordination meeting Scheduled food security the area once each year involving all members/SEGWAY to formulate and plan the program of activities, strategies, and objectives are shared on the basis of the input of the entire Member/SKPD implemented integrated by involving the entire SEGWAY SOPs related to clear so synchronize and aligned in the implementation. This agenda can also be used looking for solutions to the problems of agriculture and infrastructure need to be developed or improved (e.g. means of irrigation agriculture which is the responsibility of the Department of PU Fields of water resources), so integrated can be discussed together to find a solution.

3. Evaluation of the implementation of activities meetings Scheduled every 6 months, and each Member of the Board of the regional food security reported the results of its activities so that it could soon do the anticipation, against obstacles or because of circumstances and conditions must changing the strategy and objectives. This activity also aims to intensify communication between members of the Council of regional food security.

4. With planning, formulation of policies, programs and activities as well as the involvement of a clear human resources, as well as for the improvement of infrastructure and facilities the budget proposals attempted in RAPBD

5. So happens the same understanding and intact socialization and the construction of the present intensively managing apparatus and stakeholders about the program activity policies availability of rice so that it formed a strong commitment to achieve the goal.

6. Required information and communication system development based on IT to improve communication and encourage accelerated expansion of information on the availability of rice policy.

7. Limitations of human resources at the BKP and P4K especially in the areas of availability of Rice as the most competent agencies need immediately plus so BKP and $\mathrm{P} 4 \mathrm{~K}$ is not overwhelmed in dealing with the large number of problems and implementation activities Rice availability policy. 


\section{References}

Asmadi, H., \& Md Nasrudin Md Akhir (2008). Japan and East Asian Regionalism, Kuala Lumpur: East Asian Studies Department.

Daramola, B. (2005). Government policies and competitiveness of Nigerian rice economy. Paper presented at the workshop on rice policy and food security in Sub- Saharan Africa organized by Africa Rice Centre (WARDA), Cotonou, Republic of Benin, November 7-9, 2005.

International Rice Research Institute (IRRI) (2005). Facts About Cooperation- Bangladesh, Cambodia, China, India, Indonesia, Japan, Korea, Laos, Myanmar, Philippines, Thailand and Vietnam. Retrieved from http://www.irri.org/media/facts/

Lassa, J. (2009), Politik Ketahanan Pangan Indonesia 1950 - 2005, World Food Summit, Journal Ketahanan Pangan.

Lincoln, Y. S., \& Egon, G. G. (1985). Naturalistic Inquiry, SAGE Publication, California, New Delhi, London.

Mears, L. (1978). Problems of Supply and Marketing of Food in Indonesia in Repelita III. BIES, XIV(3), 52-62.

Miles, B., Mathew, A., \& Michael, H. (1992). Analisa Data Kualitatif (terjemahan). Penerbit Universitas Indonesia (Ul-Press). Jakarta.

Mirsha, U. (2010). Current Food Security and Challenges, dalam Food Security in Bangladesh, Papers presented In the National Workshop. 2010.

Moleong, L. (2000). Metode Penelitian Kualitatif, Edisi keempat, Remaja Rosda Karya, Bandung.

Sitmatupang, P. (1999). Toward Sustainable Food Security: The Need for A New Paradigm in Simatupang, P. et a/- (edisi Indonesia's Economic Crisis: Effects on Agriculture and Policy Responses. 1999. Centre for International Economic Studies. University of Adelaide 5005 Australia.

The Dojima Rice Market and the Origins of Futures Trading. Retrieved from https://edisciplinas.usp.br/pluginfile.php/151297/mod_resource/content/2/Dojima_Rice_Market_Case.pdf

\section{Copyrights}

Copyright for this article is retained by the author(s), with first publication rights granted to the journal.

This is an open-access article distributed under the terms and conditions of the Creative Commons Attribution license (http://creativecommons.org/licenses/by/4.0/). 